\title{
Mortalidad de equinos por Trypanosoma evansi en Argentina. Diagnóstico parasitológico y molecular
}

\author{
Pertile, C.N. ${ }^{1,2}$; Dubois, F. ${ }^{2}$; Medina, A.S.3; Sarmiento, N.F. ${ }^{1}$ \\ ${ }^{1}$ Instituto de Tecnología Agropecuaria (INTA), Estación Experimental \\ Mercedes, Corrientes. ${ }^{2}$ CONICET. ${ }^{3}$ Remonta veterinaria, E.A. \\ E-mail: pertile.carla@inta.gob.ar
}

\begin{abstract}
Resumen
Pertile, C.N.; Dubois, F.; Medina, A.S.; Sarmiento, N.F.: Mortalidad de equinos por Trypanosoma evansi en Argentina. Diagnóstico parasitológico y molecular. Rev. Vet. 32: 1, 117-119, 2021. Trypanosoma evansi, el agente causal de la tripanosomosis, afecta a una amplia variedad de animales domésticos y silvestres, siendo los equinos los principales enfermados. El objetivo de este trabajo fue describir un brote de tripanosomosis por T. evan$s i$ en veinte (20) equinos con sintomatología caracterizada por una progresiva pérdida de peso, inapetencia, hipertermia intermitente, debilidad, linfoadenomegalia, mucosas pálidas, secreciones nasales, epífora, edemas en zona de pecho, abdomen y miembros posteriores. El diagnóstico parasitológico y molecular fue positivo para T. evansi. Los animales fueron tratados con aceturato de diminacina sin resultados satisfactorios. Este trabajo es el primer reporte de mortandad de equinos por T. evansi con diagnóstico parasitológico y molecular, en la localidad de Monte Caseros, Corrientes, Argentina.
\end{abstract}

Palabras clave: Trypanosoma evansi, equinos, brote, Corrientes (Argentina).

\begin{abstract}
Pertile, C.N.; Dubois, F.; Medina, A.S.; Sarmiento, N.F.: Mortality of equines for Trypanosoma evansi in Argentina. Parasitological and molecular diagnostic. Rev. Vet. 32: 1, 117-119, 2021. Trypanosoma evansi is the causative agent of trypanosomosis and affects a wide variety of domestic and wild animals, with horses being the main affected. The objective of this work is to describe an outbreak of try panosomosis due to T. evansi in twenty (20) horses with sy mptoms characterized by progressive weight loss, loss of appetite, intermittent hyperthermia, weakness, lymphoadenomegaly, pale mucous membranes, nasal secretions and epiphora, edemas in the chest area, abdomen and later members. The diagnosis was positive for T. evansi. The treatment consisted of diminacin aceturate without satisfactory results. This work is the first report of death of horses by T. evansi with parasitological and molecular diagnosis in the town of Monte Caseros, Corrientes, Argentina.
\end{abstract}

Key words: Trypanosoma evansi, equines, outbreak, Corrientes (Argentina).

\section{INTRODUCCIÓN}

Los trypanosomas son hemoparasitos flagelados pertenecientes al orden Kinetoplastida, familia Trypanosomatidae, género Trypanosoma ${ }^{7}$. En América del Sur se transmiten de forma mecánica por insectos hematófagos, principalmente Tabanus $s p^{9}$. A diferencia de otros tripanosomas africanos, no se multiplica ni implementa ningún desarrollo cíclico en su vector ${ }^{10}$.

Se puede implementar una transmisión propagativa a través de murciélagos vampiros (Desmodus rotundus) en los que el parásito invade y se multiplica en la sangre, antes de invadir las glándulas salivales, desde donde podría ser reinyectado a un nuevo huésped. Además, es posible la transmisión vertical iatrogénica ${ }^{1}$. Dentro del hospedador mamífero, Trypanosoma evansi es principalmente un parásito sanguíneo, pero también se puede encontrar en fluidos vasculares adicionales ${ }^{9}$.

T. evansi afecta a una amplia variedad de animales domésticos y silvestres, siendo los equinos los principales afectados. Causa graves pérdidas económicas porque afecta la fertilidad y productividad de los animales ${ }^{3}$.

En la zona norte de Argentina ataca de preferencia a equinos, causando una enfermedad denominada "mal de caderas", caracterizada por la aparición de fiebre, anemia, pérdida de peso corporal, edemas y ocasionalmente trastornos locomotores, abortos e incluso la muerte ${ }^{5}$.

El diagnóstico de esta enfermedad se realiza principalmente en base a síntomas clínicos, frotis de sangre y PCR. Otros análisis paraclínicos como hemograma completo, hepatograma y función renal, también ayudan a orientar el diagnóstico ${ }^{7}$. El control de la tripa- 
nosomiasis en animales implica el seguimiento de la enfermedad y el uso de fármacos, aunque la resistencia a éstos es cada vez más común ${ }^{11}$.

La quinapiramina, suramina y melarsomina se utilizan principalmente como agentes terapéuticos para las infecciones por T. evansi, aunque la quinapiramina también se utiliza con fines profilácticos ${ }^{8}$. Estas drogas no están disponibles para su uso en Argentina. siendo la diminazina la especialidad más comúnmente empleada en equinos, a una dosis de $3,5-7 \mathrm{mg} / \mathrm{kg}$ y la vía de administración es intramuscular profunda ${ }^{4}$.

Las tácticas de control de vectores disponibles y ambientalmente aceptables son costosas y suelen producir reinfestación. A pesar del hecho de que muchos aspectos bioquímicos y moleculares de estos patógenos han sido claramente establecidos, el control de la enfermedad suele causar resultados insatisfactorios ${ }^{11}$.

Si bien no se dispone de vacunas contra los tripanosomas animales, la tripano-tolerancia, es decir la capacidad innata de ciertas razas para tolerar los tripanosomas africanos y seguir siendo productivas, ha sido descrita como una opción económica y sostenible para combatir estos parásitos ${ }^{11}$.

Otro estudio menciona que la mayoría de los casos de tripanosomosis descritos en el norte de Argentina, solo se basan en observaciones de frotis de sangre, existiendo la necesidad urgente de estudios moleculares para identificar con precisión cuáles son las especies circulantes ${ }^{6}$.

El objetivo de este trabajo fue describir un brote de mortandad de equinos por $T$. evansi con diagnóstico parasitológico y molecular, en la localidad de Monte Caseros Corrientes, Argentina.

\section{MATERIAL Y MÉTODOS}

Antecedentes. A mediados de julio de 2019 se detectó el primer caso en un establecimiento de Monte Caseros, Corrientes. Se trató de un padrillo PSC de 10 años, en un potrero de la costa del río Uruguay, asignándose este potrero como foco de origen.

Descripción de los casos clínicos. En el periodo transcurrido entre agosto de 2019 hasta julio de 2020 ocurrieron 19 muertes de equinos con sintomatología caracterizada por una progresiva pérdida de peso, inapetencia, hipertermia intermitente, debilidad, linfoadenomegalia, mucosas pálidas, secreciones nasales y epífora, edemas en zona de pecho, abdomen y miembros posteriores. Los animales fueron tratados con aceturato de diminacina a dosis de $7 \mathrm{mg} / \mathrm{kg}$ intramuscular dividida en 3 partes cada $3 \mathrm{~h}$, con la aplicación previa de un corticoide, sin resultados satisfactorios. El cuadro clínico duró aproximadamente un mes hasta la muerte de los animales. Los hallazgos de necropsia fueron: atrofia muscular del dorso, parrilla costal y de los cuartos traseros, ictericia y edema subcutáneo. Esplenomegalia, petequias superficiales, hepatomegalia, poliadenomegalia y petequias en órganos internos como intestinos, se observaron además hidrotórax y ascitis. En los pulmones se observó gran congestión y edema.

Recolección y procesamiento de muestras. Se tomaron muestras de sangre periférica de vena yugular con anticoagulante, para análisis molecular y hemograma, así como extendidos de sangre capilar de punta de oreja para análisis citológico. Los extendidos fueron fijados con metanol y coloreados con Giemsa. La observación con microscopio óptico se efectuó con un Zeiss Primo Star, bajo objetivo 100x de inmersión. Se realizó método de concentración de sangre en tubo capilar para observar presencia de hemoparásitos en buffy coat $^{2}$. Se realizó la extracción de ADN genómico de sangre entera por medio de un kit comercial (INBIO Highway). Para el diagnostico por PCR se utilizaron los primers descriptos por Konnai. Los primers utilizados fueron:

5'-CTGAAGAGGTTGGAAATGGAGAAG-3' (fordward) y Y5'-GTTTCGGTGGTTCTGTTGTTGTTA-3' (reverse)

Ellos generaron un amplicon de 151 pares de bases y se unieron a una región conservada de la glicoproteína variable de superficie (VSG) de T. evansi. Se utilizaron controles positivos y negativos adecuados. Los productos de la reacción fueron analizados en un gel de agarosa al $2 \%$ teñido con bromuro de etidio.

\section{RESULTADOS}

El diagnóstico molecular fue positivo para Trypanosoma evansi. En cuanto al diagnóstico citológico, se detectaron estructuras libres de un tamaño aproximado de 25 a 30 micras, azuladas, con presencia de núcleo y kinetoplasto, membrana ondulante y flagelo. Se observaron reticulocitos, cuerpos de Howell-Jolly y polimorfismo en eritrocitos. Además, se visualizaron parásitos en movimiento en buffy coat.

\section{DISCUSIÓN}

La tripanosomosis causa importantes pérdidas por mortalidad en equinos y el control de la enfermedad ha resultado insatisfactorio en el país hasta este momento. La mayoría de los casos descritos en el norte de Argentina solo se basaron en observaciones de frotis de sangre.

Resulta de interés científico y productivo, establecer estudios moleculares para identificar con precisión cuáles son las especies circulantes en la región, los animales afectados y la interacción entre ellas y los vectores, para poder lograr nuevos y mejores programas de control de vectores y -sobre todo- drogas más seguras para tratamientos efectivos.

Este trabajo es el primer reporte de mortandad de equinos por Trypanosoma evansi con diagnóstico parasitológico y molecular en la localidad de Monte Caseros Corrientes, Argentina. 


\section{REFERENCIAS}

1. Brun R, Hecker H, Lun ZR. 1998. Trypanosoma evansi and T. equiperdum: Distribution, biology, treatment and phylogenetic relationship (a review). Vet Parasitol 79: $95-$ 107.

2. Chagas CR, Binkienè R, Ilgūnas $M$, Iezhova $T$, Valkiūnas G. 2020. The buffy coat method: A tool for detection of blood parasites without staining procedures. Parasites \& Vectors v.13.

3. Fereig RM et al. 2017. Seroprevalence of Babesia bovis, B. bigemina, Trypanosoma evansi and Anaplasma marginale antibodies of cattle in southern Egypt. Ticks Tick Borne Dis 8: 125-131.

4. Gillingwater $\mathbf{K}$ et al. 2010. In vitro activity and preliminary toxicity of various diamidine compounds against Trypanosoma evansi. Vet Parasitol 169: 264-272.

5. Monzón CM, Hoyos CB, Jara GA. 1995. Brotes de tripanosoma equina causados por T. evansi en Formosa, Argentina. Rev Sci Tech OIE 14: 747-752.

6. Paoletta MS et al. 2018. Epidemiology of Babesia, Anaplasma and Trypanosoma species using a new expanded reverse line blot hybridization assay. Ticks Tick Borne Dis 9: $155-163$.
7. Parodi Pet al. 2018. Diagnóstico parasitológico y molecular de tripanosomiasis canina por Trypanosoma evansi en perros asociados a la caza, en dos localidades del Departamento de Artigas, Uruguay. Vet 54.

8. Peregrine AS. 1994. Chemotherapy and delivery systems: haemoparasites. Vet Parasitol 54: 223-248.

9. Sudarto MW, Tabel H, Haines DM. 1990. Immunohistochemical demonstration of Trypanosoma evansi in tissues of experimentally infected rats and a naturally infected water buffalo (Bubalus bubalis). J Parasitol 76: 162-167.

10. Sumba AL, Mihok S, Oyieke FA. 1998. Mechanical transmission of Trypanosoma evansi and T. congolense by Stomoxys nigerand $S$. taeniatusin a laboratory mouse model. MedVet Entom 12: 417-422.

11. Wilkowsky SE. 2018. Trypanosoma. In: Parasitic protozoa of farm animals and pets. Springer International Publishing 2018: 271-287. 